\title{
A scientific note on the effect of oxalic acid on honey bee larvae
}

\author{
Bethany Terpin ${ }^{1}$, Deja Perkins ${ }^{2}$, Stephanie Richter ${ }^{3}$, Jennifer Kraft Leavey ${ }^{4}$, Terry W. Snell ${ }^{4}$, John A. Pierson $^{3}$ \\ ${ }^{1}$ Environmental Science Program, Berry College, Rome, GA, USA \\ ${ }^{2}$ Fisheries, Wildlife, and Conservation Biology Program, NC State University, Raleigh, NC, USA \\ ${ }^{3}$ Georgia Tech Research Institute, Georgia Institute of Technology, Atlanta, GA, USA \\ ${ }^{4}$ School of Biological Sciences, Georgia Institute of Technology, 266 4th St., Room 365A CULC, Atlanta, GA 30332-0900, USA
}

Received 9 November 2017 - Revised 20 February 2019 - Accepted 26 April 2019

\begin{abstract}
The approval of oxalic acid as a treatment for Varroa destructor infestation of honey bee hives gives beekeepers an additional option for controlling this devastating parasite and disease vector, but the effects of oxalic acid on developing bees are not completely understood. In this study, we find that doses of oxalic acid not reported to be toxic to adult bees are toxic to larval bees. While it has been recommended that oxalic acid only be used during broodless periods because it does not penetrate cappings and is only effective in killing phoretic mites, it is tempting to use it at other times of the year because of the dearth of effective treatment options. Knowing whether oxalic acid is toxic to larvae and at what doses is important for beekeepers as they manage their colony population throughout the year.
\end{abstract}

\section{Varroa destructor / oxalic acid / honey bee / Apis mellifera}

The mite Varroa destructor is a major pathogen of honey bees and a leading cause of colony collapse. Mites have evolved resistance to first-generation treatments such as amitraz, fluvalinate, and coumaphos (Sammataro et al. 2005) prompting researchers to explore alternatives such as oxalic acid (OA) which was approved for use in honey bee hives by the EPA in 2015. OA is acutely toxic to mites and is also toxic to adult bees at high concentrations (Aliano et al. 2006; Martín-Hernández et al. 2007; Toomemaa et al. 2010). There are some data that suggest $\mathrm{OA}$ is toxic to honey bee larvae (Hatjina and Haristos 2005), possibly by inducing cell death (Gregorc et al. 2004), but the extent of OA toxicity to larvae is not known. It is recommended that OA be applied in the fall or winter when larvae levels are low, but many beekeepers are so desperate to reduce mite burden that they are using it at other times of the year (personal communications). The goal of this study is to determine the mortality rates of $\mathrm{OA}$ and associated lethal concentration (LC50) for honey bee larvae. Larval culture and toxicity

Corresponding author: J. Leavey, jennifer.leavey@biosci.gatech.edu Manuscript editor: Peter Rosenkranz assays were conducted using a guidance document protocol developed for repeated exposure (OECD 2016).

Six groups of larvae were tested: one control $(0.00 \%)$ and five treatments of increasing concentrations of OA $(0.01 \%, 0.05 \%, 0.1 \%, 0.5 \%$, and $1.0 \%)$. Table I describes the dose per larva ( $\mu \mathrm{g} / \mathrm{larva})$ associated with each concentration. The experiment was replicated 12 times. Two larvae were assigned to each instar age and OA concentration. Larvae were collected from the Georgia Tech apiary located on the roof of the Clough Undergraduate Learning Commons in Atlanta, Georgia (33.775215, -84.396436) between May and June 2018. On Day 1 (D1), a Chinese grafting tool was used to remove larvae from the comb. The larvae were sorted into second, third, and fourth instar stages by observing the space occupied by the larva in the cell (Human et al. 2013). Larvae were placed into sterile 48well plates containing $40 \mu \mathrm{l}$ of artificial diet composed of $50 \% w / v$ royal jelly (Stakich Inc., Troy, MI) and $50 \%$ sugar/yeast solution made of $9 \% \mathrm{w} / \mathrm{v} \mathrm{D}$-glucose (VWR, Radnor, PA), 9\% w/v D-fructose (VWR, Radnor, PA), and $2 \% w / v$ bacto-yeast (VWR, Radnor, PA) in deionized water. Grafting was restricted to $60-\mathrm{min}$ duration to limit larval stress. Larvae were cultured at $35^{\circ} \mathrm{C}$ and $90 \%$ humidity for the duration of the experiment (D1 to D5). Larvae were not fed on D2 as this 


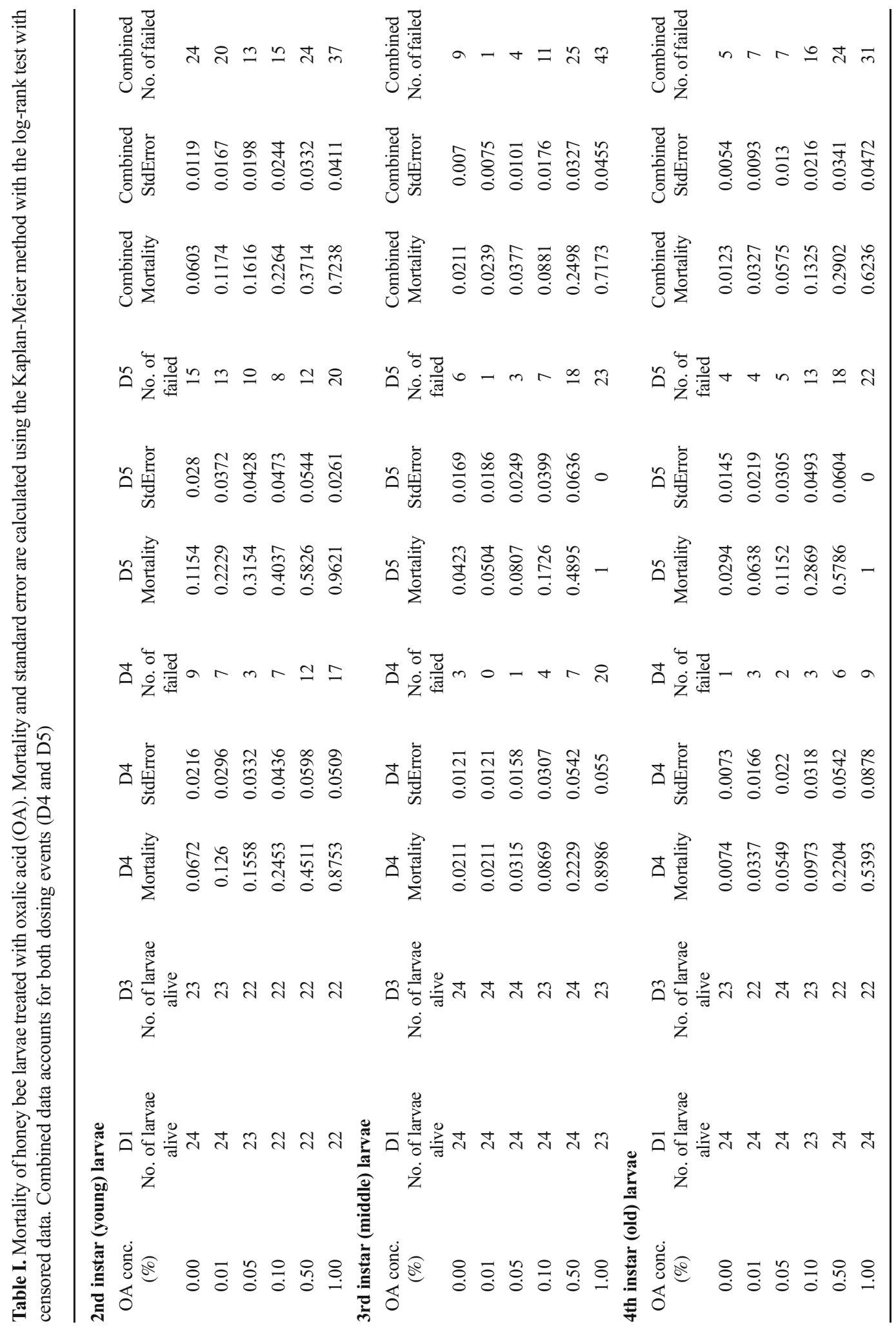




\section{Hours Post-Treatment Instar Survival}

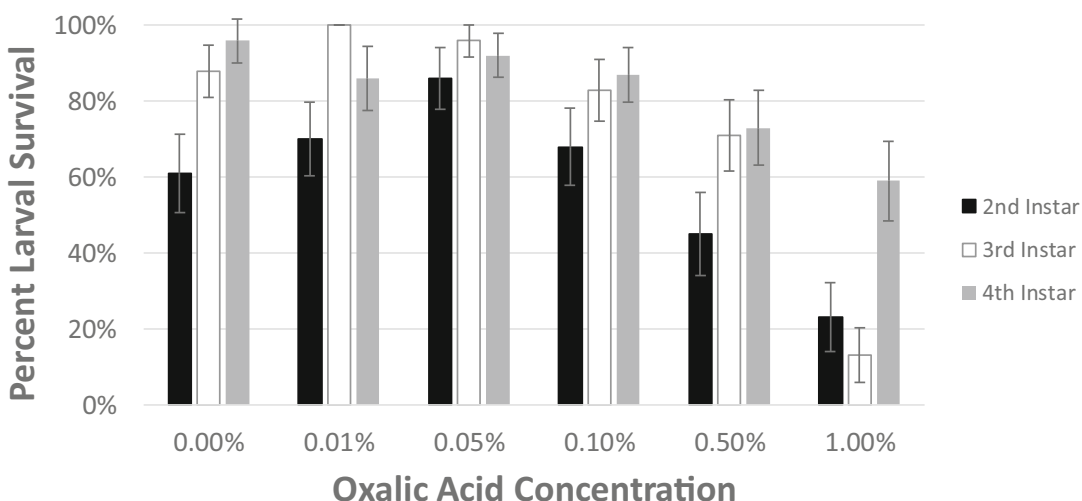

Figure 1. Instar larval mortality $24 \mathrm{~h}$ post initial feeding (D4). Graphs show mortality $24 \mathrm{~h}$ after first feeding. The horizontal axis (abscissa) is the percent concentration of oxalic acid (OA) versus vertical (ordinate) percentage larval survival. Error bars represent the calculated standard error.

served as an environmental acclimation period. On D3, larvae were checked for movement via a dissecting microscope. Larvae demonstrating movement of any kind were deemed alive and continued in the experiment. On D3 and D4, all live larvae were fed artificial diet with the appropriate concentration of $\mathrm{OA}$ for their treatment group. The volume of diet varied by instar stage in order not to suffocate the larvae. Larvae in the second instar stage were fed $20 \mu$ l, third instar larvae were fed $50 \mu \mathrm{l}$, and fourth instar larvae were fed $100 \mu \mathrm{l}$.
After $24 \mathrm{~h}$, on D4, larvae were checked for movement as an indicator of survival. All surviving larvae were again fed their corresponding OA concentration diet. The experiment concluded on D5.

Statistical analysis was conducted using SAS JMP Pro version 14.1.0 software. The KaplanMeier method with the log-rank test and censored data was used for comparing survival curves. The Cox proportional hazards regression was used to examine risk ratios between covariates. Significance

\section{Hours Post-Treatment Instar Survival}

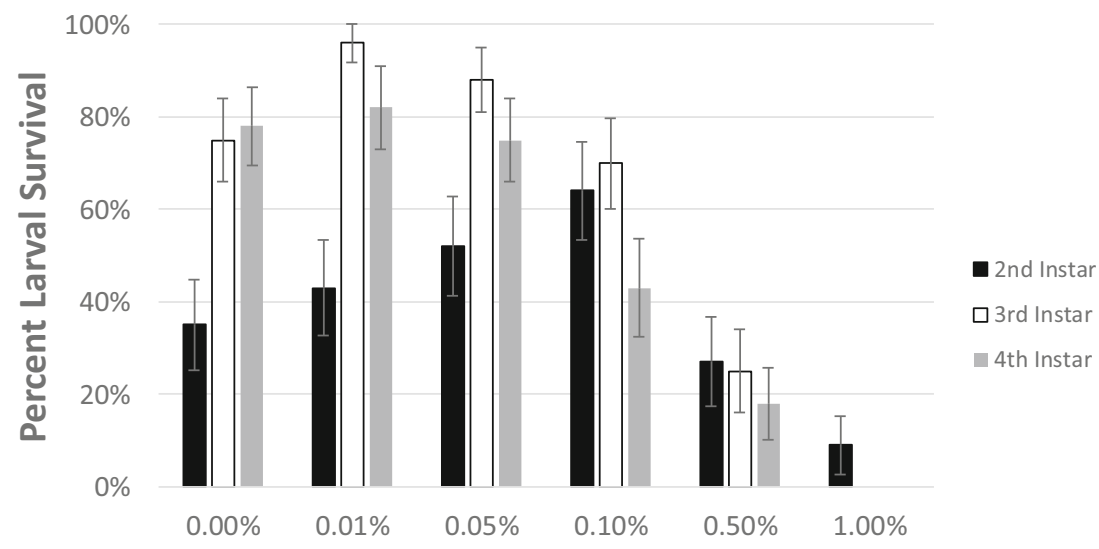

\section{Oxalic Acid Concentration}

Figure 2. Instar larval mortality $48 \mathrm{~h}$ post initial feeding (D5). Graph depicts mortality $48 \mathrm{~h}$ after first feeding. Larvae were fed on D3 and D4. The horizontal axis (abscissa) is the percent concentration of oxalic acid (OA) versus vertical (ordinate) percentage larval survival. Error bars represent the calculated standard error. 


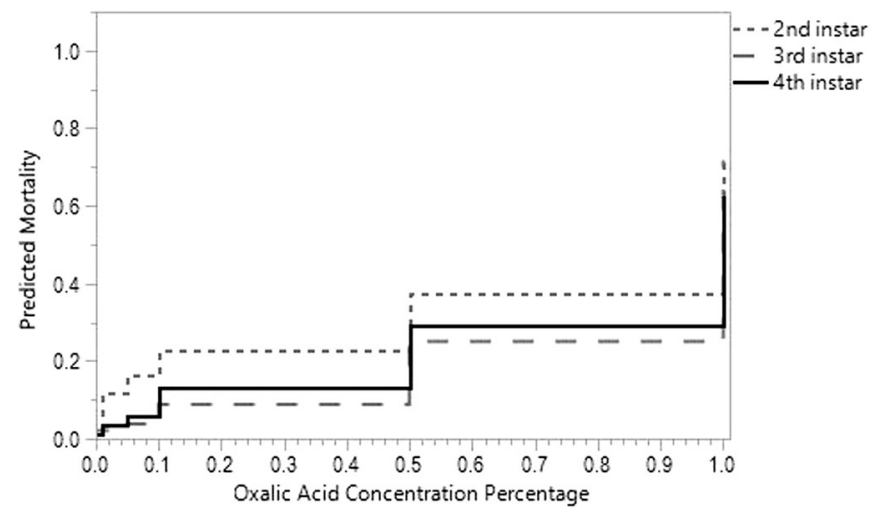

Figure 3. Kaplan-Meier predicted mortality rates by instar described by OA percentage concentrations.

was defined as $p$ values $<0.05$. The median lethal dose (LC50) of combined dose exposure was with confidence limits of $95 \%$ using a generalized regression dose-response.

In total, 423 larvae were grafted on D1. On D3, the 412 surviving larvae continued into the study. After $24 \mathrm{~h}$ of treatment (D4), all instar groups showed decreased survival at each OA concentration higher than $0.05 \%$ (Figure 1). Older larvae were more resistant to treatment than younger larvae. After $48 \mathrm{~h}$ of treatment, survival rates of larvae in all instar phases were lower than at $24 \mathrm{~h}$ and older larvae had higher survival rates than younger larvae (Figure 2).

Mortality rates of the second, third, and fourth instar groups for the 12 replicates are shown in Table I, and Figure 3 depicts the associated Kaplan-Meier predicted mortality. While the effects of dosing on instar by

Table II. Cox proportional hazard model establishing the hazard risk ratios associated with random effects of the single and double dosing on instar mortality, the added effect of OA concentrations, and the binary effects of OA concentration on each instar by dosing

\section{Effects of instar}

$\begin{array}{clcccc}\text { Level 1 } & \text { Level 2 } & \text { Risk ratio } & \text { Prob > Chisq } & \text { Lower 95\% } & \text { Upper 95\% } \\ \text { 4th instar } & \text { 3rd instar } & 1.0327 & 0.6819 & 0.8855 & 1.2043 \\ \text { 2nd instar } & \text { 3rd instar } & 1.1098 & 0.2059 & 0.9443 & 1.3043 \\ \text { 2nd instar } & \text { 4th instar } & 1.0747 & 0.3864 & 0.9130 & 1.2651\end{array}$

\section{Effects of instar and $\mathrm{OA}$ percentage concentration percentages}

\begin{tabular}{|c|c|c|c|c|c|}
\hline Term & & Risk ratio & & Lower 95\% & Upper $95 \%$ \\
\hline OA conc. & & 1.7625 & & 1.4160 & 2.1779 \\
\hline Level 1 & Level 2 & Risk ratio & Prob $>$ Chisq & Lower 95\% & Upper $95 \%$ \\
\hline 4th instar & 3 rd instar & 1.0140 & 0.8595 & 0.8693 & 1.1828 \\
\hline 2nd instar & 3rd instar & 1.0780 & 0.3636 & 0.9168 & 1.2675 \\
\hline 2nd instar & 4th instar & 1.0631 & 0.4623 & 0.9031 & 1.2515 \\
\hline
\end{tabular}

\section{Effects of the binary interactions of instar and dose concentration percentages}

\begin{tabular}{|c|c|c|c|c|c|}
\hline Term & & Risk ratio & & Lower $95 \%$ & Upper $95 \%$ \\
\hline OA conc. & & 3.9993 & & 3.0704 & 5.2092 \\
\hline Level 1 & Leve 12 & Risk ratio & Prob $>$ Chisq & Lower 95\% & Upper $95 \%$ \\
\hline 4th instar & 3rd instar & 1.2015 & 0.3044 & 0.8464 & 1.7056 \\
\hline 2nd instar & 3rd instar & 2.0618 & $<0.0001$ & 1.5050 & 2.8245 \\
\hline 2nd instar & 4th instar & 1.7160 & 0.0003 & 1.2804 & 2.2997 \\
\hline
\end{tabular}


Table III. Estimated lethal concentration (LC50) of oxalic acid for honey bee larvae

\begin{tabular}{lrrr}
\hline $\begin{array}{l}\text { Instar } \\
\text { class }\end{array}$ & $\begin{array}{l}\text { Predicted OA } \\
\text { concentration }\end{array}$ & $\begin{array}{l}\text { Lower } \\
95 \%\end{array}$ & $\begin{array}{l}\text { Upper } \\
95 \%\end{array}$ \\
\hline 2nd & 0.649 & 0.553 & 0.759 \\
3rd & 0.972 & 0.853 & 1.118 \\
4th & 0.959 & 0.838 & 1.105 \\
\hline
\end{tabular}

concentration were established, mortality data was fitted with the Cox proportional hazard model to further establish the hazard risk ratios associated with random effects of the single and double dosing on instar mortality, the added effect of OA concentration, and the binary effects of OA concentration on each instar by dosing. Table II depicts the results which show that while second instar mortality is more likely relative to the third and fourth instars after double dosing (see Risk Ratio), $p$ values are not significant. Adding the continuous predictor of OA percentages and removing the effects of instar groups, larvae mortality is 1.76 times more from increasing OA percentages. After removing the effects of OA concentration at any given time, larvae mortality by instar remains relatively constant with insignificant $p$ values. However, increasing OA percentages indicates a 3.99 greater likelihood of mortality across instars. The second instar is $2.06(p<0.0001)$ times more likely to die relative to the third instar and $1.71(p<0.0003)$ times relative to the fourth instar. Table III shows the estimated OA lethal concentration (LC50) for each instar. The third and fourth instar larvae showed higher LC50 values compared with the second instar larvae following the trends found in Table II.

Because larvae are protected in brood cells, it is unlikely that they are exposed to the full 3-5\% concentration of OA recommended by the EPA for treatment of mites by the solution method of administration. The lower concentration ranges of oxalic acid (0.01-1.0\%) used in this study tested may more closely match levels larvae experience due to adsorption of the surrounding colony matrix in response to trickling, spraying, sublimation, or transport of the pesticide through the hive by tracking of adult bees. After a single exposure, the third and fourth instar larvae had higher survival rates in each treatment group compared with the second instar larvae indicating that older larvae have a greater tolerance for the pesticide. A significant decrease in survival in all larvae $48 \mathrm{~h}$ post treatment was documented.

Sources of variability in mortality could result from back-to-back OA feedings, time and order of grafting (control groups grafted first allowing for more exposure to environment), larvae classified as live/dead with no intermediate morbidity defined or recorded, and no change in diet composition as the larvae age. Another consideration is that while adult pesticide studies are reported as oral or dermal application, no distinction is proven as larvae are immersed in the solution containing the prescribed OA percentage concentration. Further work is needed to determine if the mortality rates resulted from repeated exposure of double dosing of $\mathrm{OA}$, or simply the presence of OA in the diet after single intervention. That experimental design could include intermittent feeding such as $24 \mathrm{~h}$ and $72 \mathrm{~h}$.

While oxalic acid at EPA-recommended treatment levels of $5 \mathrm{ml}$ at $3-5 \%$ of OA in sugar water has been found to be safe for adult bees, this study shows that oxalic acid is very toxic to honey bee larvae. The current study provides a reasonable model of larval exposure to $\mathrm{OA}$ in treated beehives. Beekeepers should be aware that using OA for mite control while larvae are present could have a negative downstream effect on the colony population size and wintering capability.

\section{AUTHORS' CONTRIBUTION}

All authors have contributed equally to this work.Funding information

This work was funded by the U.S. Department of Agriculture, National Institute of Food and Agriculture grant no. 2016-67032-24986.

Une note scientifique sur l'effet de l'acide oxalique sur les larves d'abeilles

Varroa destructor / acide oxalique / Apis mellifera

Eine wissenschaftliche Notiz über den Effekt von Oxalsäure auf Honigbienenlarven.

Varroa destructor / Oxalsäure / Honigbiene / Apis mellifera

\section{REFERENCES}

Aliano, N.P., Ellis, M.D., Siegfried, B.D. (2006) Acute Contact Toxicity of Oxalic Acid to Varroa destructor (Acari: Varroidae) and Their Apis mellifera (Hymenoptera: Apidae) Hosts in Laboratory Bioassays. J. Econ. Entomol. 99(5), 1579-1582

Gregorc, A., Pogacnik, A., Bowen, I.D. (2004) Cell death in honeybee (Apis mellifera) larvae treated with oxalic or formic acid. Apidologie. 35(5), 453-460 
Hatjina, F., Haristos, L. (2005) Indirect effects of oxalic acid administered by trickling method on honey bee brood. J. Apic. Res. 44 (4), 172-174

Human, H., Brodschneider, R., Dietemann, V., et al. (2013) Miscellaneous standard methods for Apis mellifera research. J. Apic. Res. 52 (4), 1-53

Martín-Hernández, R., Higes, M., Pérez, J.L., Nozal, M.J., Gómez, L., Meana, A. (2007) Short term negative effect of oxalic acid in Apis mellifera iberiensis. Span. J. Agric. Res. 5(4), 474-480

OECD (2016) Guidance Document on Honey Bee (Apis mellifera) Larval Toxicity Test, Repeated Exposure, Series on Testing and Assessment No. 239. Organization for Economic Cooperation and Development. ENV/JM/MONO(2016)34
Sammataro, D., Untalan, P., Guerrero, F., Finley, J. (2005) The resistance of varroa mites (Acari: Varroidae) to acaricides and the presence of esterase. Int. J. Acarol. 31 (1), 67-74

Toomemaa, K., Martin, A.-J., Williams, I.H. (2010) The effect of different concentrations of oxalic acid in aqueous and sucrose solution on Varroa mites and honey bees. Apidologie. 41 (6), 643-653

Publisher's note Springer Nature remains neutral with regard to jurisdictional claims in published maps and institutional affiliations. 